\title{
O Impacto de Brises na Ventilação Natural: Avaliação Integrada em uma Enfermaria em Florianópolis (SC)
}

\author{
DE QUADROS, Bianca Milani ${ }^{1}$ \\ ORDENES, Martin ${ }^{2}$ \\ 1 Universidade Federal de Santa Catarina, Florianópolis-SC, Brasil. bianca@labcon.ufsc.br \\ 2 Universidade Federal de Santa Catarina, Florianópolis-SC, Brasil. martin@arq.ufsc.br
}

\section{Resumo}

A principal função dos brises é o controle do ganho de calor pelas janelas. No entanto, estes elementos também podem influenciar no desempenho da ventilação natural. Em edifícios hospitalares, a ventilação natural pode reduzir o consumo de energia, proporcionar conforto térmico e controlar a infecção hospitalar por meio da renovação do ar nos ambientes onde não há obrigatoriedade do uso de sistemas de ar condicionado. Este artigo analisa o impacto de brises no desempenho da ventilação natural em uma enfermaria em Florianópolis (SC). Para uma análise detalhada, o estudo integrou simulações computacionais com modelos de rede e CFD. Foram simulados dois casos: caso 1 que reproduz o ambiente existente sem brises e o caso 2 que apresenta o mesmo ambiente com brises em todas as janelas. Os resultados demonstram que a aplicação de brises modifica o comportamento da ventilação natural com o aumento da velocidade do ar de entrada e, consequentemente, com a elevação da velocidade média do ar interno. Conclui-se que os brises apresentam não apenas a usual finalidade de redução do ganho de calor, mas também podem auxiliar na melhoria do desempenho da ventilação natural.

Palavras-Chave: Conforto Ambiental; Ventilação; Brises; EnergyPlus; CFD.

\begin{abstract}
The main purpose of shading devices is controling windows heat gain. However, these elements can have an influence on natural ventilation control according its geometry and wind direction. In hospitals, natural ventilation can be used to reduce the energy consumption, to provide thermal comfort and to control hospital-acquired infections through air renewal for all rooms where the HVAC systems is not mandatory. This paper analyzes the impact of shading devices on the performance of natural ventilation in an infirmary room in Florianopolis, Brazil. For a detailed analysis of natural ventilation, this study combined computational simulation with Airflow Network model and CFD. Two cases were simulated: case 1 reproduces the existing building project without shading devices and case 2 analyses the same model with shading devices in all windows. Results have shown that shading devices can impose on airflow behavior increasing the inlet wind velocity and hence the internal air velocity average. In conclusion, shading devices have not only a wellknown importance on reducing solar heat gain but also they can help to improve natural ventilation performance.
\end{abstract}

Key-Words: Environmental comfort; Ventilation; Shading devices; EnergyPlus; CFD. 


\section{Introdução}

Hospitais apresentam áreas grandes que necessitam ser condicionadas para manterem satisfatórias as condições térmicas do paciente e não comprometer seu conforto e tratamento médico. Nos hospitais brasileiros de grande porte, estima-se que o condicionamento represente mais de $40 \%$ da demanda energética totais (SZKLO; SOARES; TOLMASQUIM, 2004). Todavia, áreas onde não há obrigatoriedade de condicionamento artificial possibilitam o uso de estratégias passivas que garantam o conforto térmico de seus usuários e a eficiência energética do edifício. A ventilação natural e o uso de brises são as principais estratégias para redução do consumo de energia (GRATIA; DE HERDE, 2007; SANTAMOURIS et al., 1994).

Estudos sobre a aplicação de brises em edifícios naturalmente ventilados demonstram que estes dispositivos podem contribuir para o conforto térmico e eficiência energética não apenas pelo atenuamento da radiação solar direta, mas pela melhora do desempenho da ventilação natural (LEE; ALSHAYEB; CHANG, 2015; SAFER; WOLOSZYN; ROUX, 2004). Safer et al. (2004) sugerem que brises horizontais podem aumentar a velocidade do ar interno. Lee et al. (2015) também encontraram maior efetividade de brises horizontais no desempenho térmico da edificação, considerando a ventilação natural e a radiação solar. Com relação ao consumo energético, Gratia e Herde (2007) apontam um potencial de economia de $23 \%$ durante o verão na Bélgica para edifícios com brises integrados à fachada dupla. No Brasil, mais especificamente na cidade de Florianópolis, Santana (2006) encontrou uma redução de até $11,6 \%$ no consumo de energia em um edifício de escritórios com brises verticais e horizontais com um ângulo máximo de $45^{\circ}$.

No caso dos edifícios hospitalares, a utilização de brises e a adoção da ventilação natural podem auxiliar o processo de cura dos pacientes proporcionando conforto térmico e renovação do ar para o controle de infecção hospitalar (ADAMU; PRICE; COOK, 2012). Até meados do século XX, a primeira razão para ventilar seria para a dispersão de contaminantes do ar. Apenas a partir dos anos 90 cresce a importância da ventilação para o conforto térmico (SANTAMOURIS; WOUTERS, 2006). Isto implica em discussões sobre o modelo estático de conforto térmico. O simples balanço de calor do corpo humano proposto por este modelo não pode representar o conforto térmico dos ocupantes de ambientes ventilados naturalmente. Ajustes comportamentais, fisiológicos e psicológicos devem ser levados em consideração. A modificação do movimento do ar ao redor do corpo humano, por exemplo, pode acelerar a troca de calor por convecção e ainda pode afetar diretamente as condições de conforto ao reduzir a própria carga térmica do edifício (CÂNDIDO; DE DEAR; LAMBERTS, 2011; SANTAMOURIS, 1998).

Estudos demonstram que pessoas em ambientes condicionados artificialmente são mais exigentes com relação à temperatura do ambiente do que quando expostas à ventilação natural (SANTAMOURIS; WOUTERS, 2006). Baseados nestes estudos, foi proposto o modelo adaptativo de conforto térmico para integrar a norma ASHRAE Standard 55 (ASHRAE, 2013). Hwang et al. (2007) investigaram a aplicabilidade desta normativa em hospitais condicionados artificialmente. Os resultados revelam compatibilidade entre a zona de conforto estabelecida pela normativa e observada no estudo de campo. No entanto, constatou-se que os pacientes preferem sentir-se levemente com calor do que em neutralidade térmica.

A simulação computacional do movimento do ar pode ser uma ferramenta importante para a compreensão do comportamento da ventilação natural e seus benefícios em edifícios hospitalares. Santamouris (1998) classifica as ferramentas de simulação da ventilação em quatro diferentes modelos: modelos empíricos, modelos de redes, modelos zonais e modelos CFD (fluidodinâmica computacional). Os modelos de rede, como o Airflow Network do software EnergyPlus, consideram a edificação como uma rede onde cada zona da edificação pode ser representada por um nó (com temperatura, pressão, velocidade do ar, etc) e o ambiente externo é representado por um nó em cada fachada. As interações entre as zonas e o ambiente externo são representadas por conexões de fluxo ar como janelas, frestas e portas. Para todos os nós zonais e externos são atribuídos valores de pressão. No entanto, análises mais 
detalhadas sobre a distribuição, velocidade, temperatura e pressão do fluxo de ar no ambiente interno em uma dada fração de tempo necessitam de modelos CFD (ZHAI, 2006). Muitos estudos integram diferentes modelos para reduzir suas limitações (ADAMU; PRICE; COOK, 2012; ZHANG et al., 2013).

A presente pesquisa analisa a influência de brises no desempenho da ventilação natural em uma enfermaria em Florianópolis (Brasil) por meio da integração entre os modelos de rede e CFD. O quarto de enfermaria do estudo de caso é um projeto padrão para Unidades de Emergência estabelecidos pelo Ministério de Saúde com o intuito de expandir a atenção primária à saúde no Brasil.

\section{Procedimentos para avaliação do comportamento da ventilação natural}

Para uma análise detalhada, o estudo integra os modelos de rede CFD por meio dos softwares EnergyPlus e Phoenics, respectivamente. Enquanto o uso do modelo de rede permite a análise do ganho de calor pela janela e trocas de ar; o modelo CFD revela a distribuição da velocidade do ar interno. Conforme ilustra a Figura 1, foram simulados dois casos: caso 1 (caso base) que reproduz o ambiente existente sem brises e o caso 2 que apresenta o mesmo ambiente com brises em todas as janelas.

Figura 1: Modelo do EnergyPlus para o caso base (à esquerda) e caso 2 (à direita).

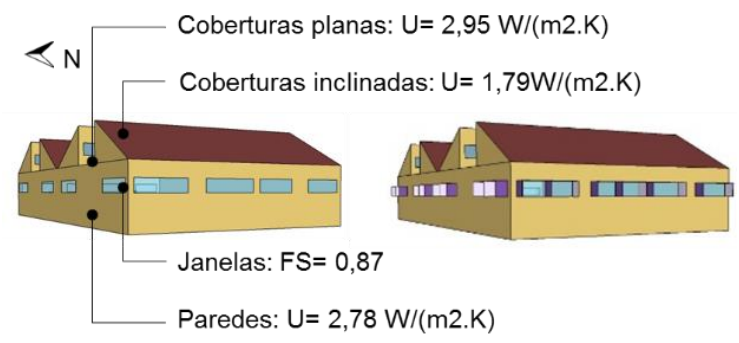

Fonte: Os autores.

Conforme ilustra a Figura 2, a proteção solar das janelas do caso 2 é feita por um brise horizontal no limite superior das janelas e dois brises verticais nos limites laterais com profundidades de $0,8 \mathrm{~m}$. Com esta geometria, as janelas da fachada oeste, responsável pelo maior ganho de calor no verão, permanecem $100 \%$ protegidas da incidência da radiação solar direta até às $15: 30$ hs e $50 \%$ protegidas até às $16: 30 \mathrm{hs}$ (mancha quadriculada) no período de verão (Figura 3 ).

Figura 2: Proteção solar das janelas do caso 2.

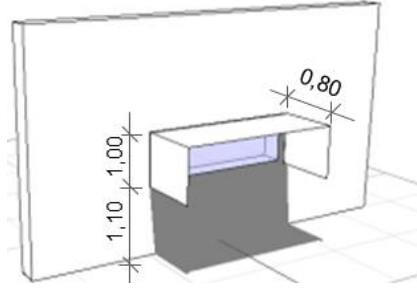

Fonte: Software Solar Tool, adaptada pelos autores.

Figura 3: Máscara de sombra para brises nas janelas oeste.

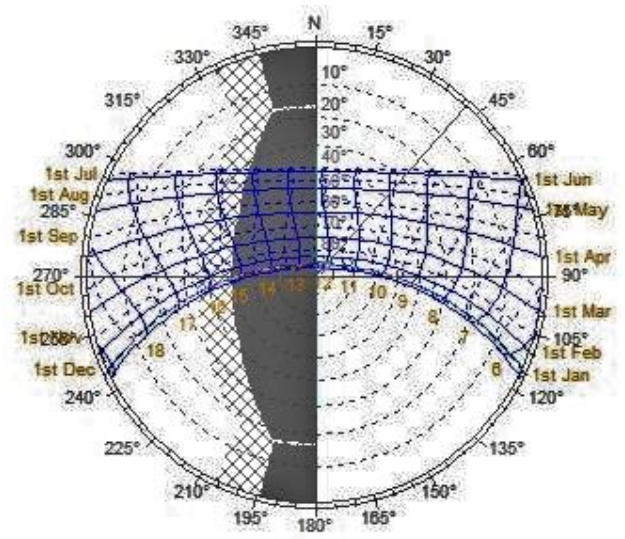

Fonte: Software Solar Tool, adaptada pelos autores.

A Figura 4 apresenta a planta baixa e o corte da enfermaria com uma área útil de $208 \mathrm{~m}^{2}$ e pé direito de $2,80 \mathrm{~m}$. O layout do ambiente é caracterizado por 13 leitos dispostos perpendicularmente às janelas e 2 postos de enfermaria no centro. Existem aberturas em três orientações: norte, leste e oeste. 
Figura 4: Planta baixa da enfermaria.
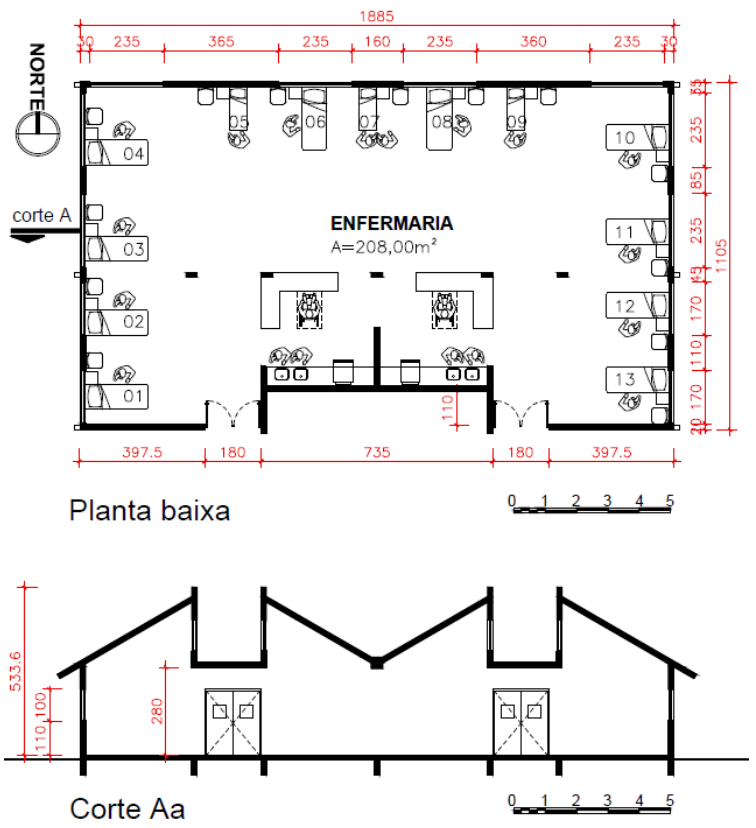

Fonte: Os autores

O clima selecionado para a simulação foi da cidade de Florianópolis, localizada na região sul do Brasil, na latitude 27,7 o $\mathrm{S}$, longitude 48,5 o $\mathrm{W}$ e a uma altitude de referência de $7 \mathrm{~m}$ em relação ao nível do mar. O zoneamento bioclimático brasileiro estabelecido pela NBR 15220 (ABNT, 2003) divide o país em oito zonas, sendo que Florianópolis encontra-se na ZB3. Seu clima é classificado como mesotérmico úmido com as estações do ano bem definidas: altas temperaturas no verão e baixas no inverno.

A partir da análise do arquivo climático TRY, foram estabelecidos dias típicos de verão com grande potencial de uso da ventilação natural. De acordo com a Figura 5, os ventos norte e nordeste ocorrem com maior frequência no verão. Para estes ventos, as velocidades do ar predominantes variam de 3 à $6 \mathrm{~m} / \mathrm{s}$. O mês de janeiro registra as maiores médias de velocidade do vento e temperaturas de bulbo seco. Desta forma, foram selecionados os dias 4 e 15 de janeiro que representam dias com grande potencial do uso da ventilação natural por apresentarem temperaturas do ar elevadas $\left(27,07^{\circ} \mathrm{C}\right.$ e $23,77^{\circ} \mathrm{C}$, respectivamente) e ventos fortes $(4,88 \mathrm{~m} / \mathrm{s}$ na direção norte e $5,21 \mathrm{~m} / \mathrm{s}$ na direção sul, respectivamente).
Figura 5: Frequência de ocorrência dos ventos e velocidade do ar predominante para o período de verão.

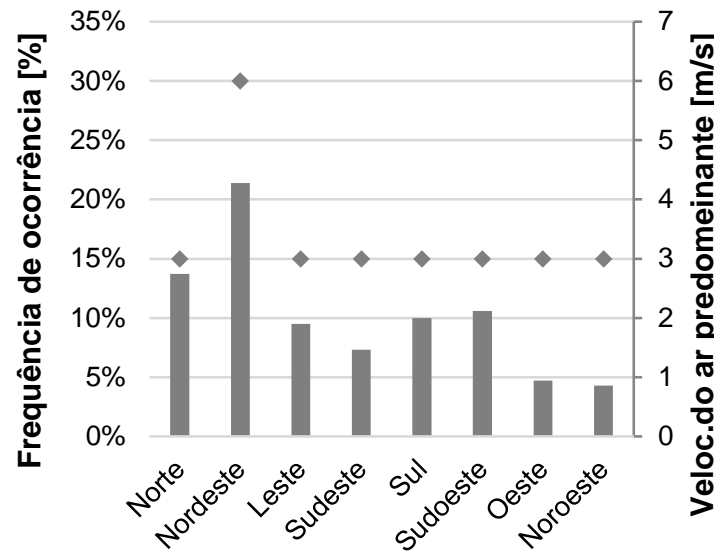

Frequência de ocorrência $\bullet$ Velocidade do ar

Fonte: Os autores.

\subsection{Modelo de rede}

O modelo de rede utiliza o software Energy Plus e adota elementos do padrão construtivo brasileiro. A tabela 1 apresenta as principais características das paredes, coberturas e janelas.

Tabela 1: Características dos elementos construtivos.

\begin{tabular}{|c|c|c|}
\hline $\begin{array}{l}\text { Elementos } \\
\text { construtivos }\end{array}$ & Materiais & $\begin{array}{l}\text { Transmitância } \\
\text { térmica ou Fator } \\
\text { Solar }\end{array}$ \\
\hline Parede & $\begin{array}{l}\text { Camada externa } \\
\text { e interna de } \\
\text { argamassa } \\
(2,5 \mathrm{~cm} \text { de } \\
\text { espessura cada) } \\
\text { e bloco de } \\
\text { concreto ( } 9 \mathrm{~cm} \\
\text { de espessura) }\end{array}$ & $\mathrm{U}=2,78 \mathrm{~W} /(\mathrm{m} 2 . \mathrm{K})$ \\
\hline Cobertura & $\begin{array}{l}\text { Coberturas } \\
\text { planas: laje pré- } \\
\text { moldada }(12 \mathrm{~cm} \\
\text { de espessura }) \\
\text { sem telhamento }\end{array}$ & $\mathrm{U}=2,95 \mathrm{~W} /(\mathrm{m} 2 . \mathrm{K})$ \\
\hline Cobertura & $\begin{array}{l}\text { Coberturas } \\
\text { inclinadas: Laje } \\
\text { pré-moldada } \\
(12 \mathrm{~cm} \text { de } \\
\text { espessura), } \\
\text { câmara de ar e } \\
\text { telha cerâmica }\end{array}$ & $\mathrm{U}=1,79 \mathrm{~W} /(\mathrm{m} 2 . \mathrm{K})$ \\
\hline Janelas & $\begin{array}{l}\text { Vidro incolor } \\
\text { simples (3mm } \\
\text { de espessura) }\end{array}$ & $\mathrm{FS}=0,87$ \\
\hline
\end{tabular}


O padrão de uso da edificação é baseado no funcionamento 24 horas do atendimento de emergência de pacientes. A Tabela 2 sintetiza os padrões de uso e as cargas térmicas resultantes do sistema de iluminação, equipamentos eletrônicos e ocupação da enfermaria. Para o sistema de iluminação, a norma brasileira recomenda uma iluminância de 500lux para salas de exames em geral. A carga térmica necessária para alcançar esta iluminância utilizando lâmpadas fluorescente (eficiência luminosa de é de $601 \mathrm{~lm} / \mathrm{W}$ ) é de $1730 \mathrm{~W}$.

Tabela 2: Padrões de uso e cargas térmicas.

\begin{tabular}{|c|c|c|}
\hline & Padrões de uso & $\begin{array}{l}\text { Carga } \\
\text { térmica }\end{array}$ \\
\hline Iluminação & $\begin{array}{l}\text { Lâmpadas são acesas } \\
\text { todos dias das } 7 \mathrm{hs} \text { às } \\
21 \mathrm{hs} \text { e apenas } 1 \% \text { das } \\
\text { lâmpadas são acesas } \\
\text { das } 21 \mathrm{~h} \text { s às } 7 \mathrm{hs} \text {. }\end{array}$ & $1730 \mathrm{~W}$ \\
\hline $\begin{array}{l}\text { Equipamentos } \\
\text { eletrônicos }\end{array}$ & $\begin{array}{l}\text { Equipamentos } \\
\text { permanecem } \\
\text { conectados o dia } \\
\text { inteiro, exceto nos } \\
\text { finais de semana } \\
\text { quando apenas 25\% } \\
\text { estão em uso. }\end{array}$ & $470 \mathrm{~W}$ \\
\hline Ocupação & $\begin{array}{l}28 \text { pessoas, sendo } 13 \\
\text { pacientes, } 13 \\
\text { acompanhantes e } 2 \\
\text { enfermeiras. A } \\
\text { ocupação máxima } \\
\text { ocorre das } 9 \text { hs às } 18 \mathrm{hs} \text {. } \\
\text { A ocupação é de } 25 \% \\
\text { nos finais de semana e } \\
\text { das } 18 \mathrm{hs} \text { às } 9 \mathrm{hs} \text { nos } \\
\text { dias de semana. }\end{array}$ & $\begin{array}{l}108 \mathrm{~W} / \\
\text { pessoa } \\
\text { (representa } \\
\text { uma pessoa } \\
\text { descansando } \\
\text { sentada) }\end{array}$ \\
\hline
\end{tabular}

Fonte: Os autores.

O sistema de ventilação adota o controle seletivo, especificando quando as aberturas devem ser abertas ou fechadas para manter a temperatura interna dentro do intervalo de conforto estabelecido. Assim, as janelas são abertas quando a temperatura interna do ar é igual ou superior à temperatura máxima de $22^{\circ} \mathrm{C}$.

No programa EnergyPlus, a maioria das informações necessárias para o cálculo do fluxo de ar é automaticamente extraída da descrição da edificação para a modelagem térmica. O objeto Airflow Network calcula o fluxo de ar entre as zonas e o exterior, através de frestas e janelas. Neste caso, por tratar-se de um ambiente único, o modelo é composto por uma zona térmica definida pelo volume da enfermaria.

Em função da geometria simples do objeto de estudo, foi utilizado o algoritmo do EnergyPlus que calcula automaticamente o Cp pela equação 1 (PEREIRA et al, 2013), (Equação 1).

$C p=0,6 \ln [1,248-0,703 \sin (\alpha / 2)-$

$1,175 \sin ^{2}(\alpha)+0,131 \sin ^{3}(2 \alpha G)+$

$0,769 \cos (\alpha / 2)+0,07 G^{2} \sin ^{2}(\alpha / 2)+$

$\left.0,717 \cos ^{2}(\alpha / 2)\right]$

Onde:

$\boldsymbol{C} \boldsymbol{p}=$ Coeficiente de pressão em um dado ângulo entre a direção do vento e a superfície considerada (adimensional);

$\boldsymbol{\alpha}=$ Ângulo entre a direção do vento e a superfície considerada;

$\boldsymbol{G}=$ Logaritmo natural da razão entre a largura da parede considerada e a largura da parede adjacente (adimensional);

ln = Índice do ângulo de incidência.

\subsection{O modelo CFD}

O modelo CFD utiliza o software Phoenics, especializado em simulação de fluxo de fluídos e de processos de trocas de calor aplicados à equipamentos de engenharia e espaços construídos. Para este último, o Phoenics dispõe do módulo FLAIR que possui uma interface mais amigável para a construção da geometria da edificação, bem como para o refinamento da malha de avaliação de acordo com a escala do ambiente a ser analisado (escala urbana ou ambiente interno).

Conforme ilustra a Figura 6, o processo de modelagem é dividido em: definição do domínio, determinação da malha de avaliação, definição do número de iterações e construção da geometria.

Figura 6: Processo de modelagem CFD.

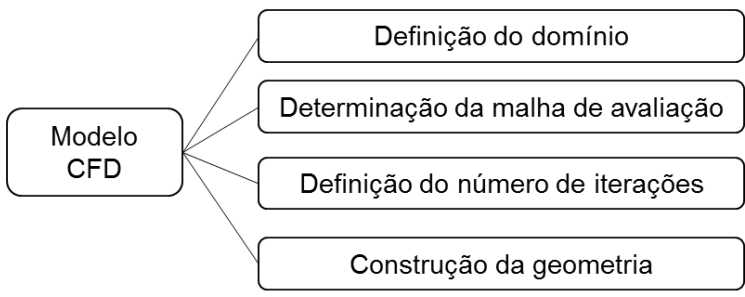

Fonte: Os autores.

A definição do domínio é feita pelo seu dimensionamento, especificação das suas condições de contorno e modelo de turbulência. Sabe-se que o 
volume do domínio deve ser grande o suficiente para que não influencie os resultados obtidos. Neste caso, foram adotadas as recomendações de Souza (2015), que aconselha que o volume do domínio seja equivalente ao dobro do volume do edifício, resultando em um domínio de 22 x 38 x 10m.

O modelo CFD permite a análise da distribuição da velocidade do ar interno, porém é limitado a uma dada fração de tempo. Para tanto, deve ser especificada as condições de contorno as quais se tem o interesse em analisar. Sendo assim, foi selecionado o horário das $14 \mathrm{hs}$ no dia 04 de janeiro por apresentar a maior temperatura e velocidade do ar externo.

Os ventos foram modelados como Wind object em estado estável para avaliação da ventilação em uma dada fração de tempo. O Wind object caracteriza as condições atmosféricas das bordas limite do domínio. Em função dos obstáculos do entorno do terreno (vegetação, edificações, topográfica e outros), a velocidade inicial é corrigida pelo programa por meio da equação 2. A velocidade corrigida depende da altura da edificação e a rugosidade do terreno. Seis níveis de classificações de rugosidade de terreno são disponibilizados. Por tratar-se de uma edificação em área urbana, assume-se nas simulações o nível 5, denominado como "Parkland, bushes, numerous obstacles", (Equação 2).

$U=U r \cdot \frac{K}{\ln } \cdot\left(\frac{Z r-d}{Z^{\circ}}\right)$

Onde:

$\boldsymbol{U}=$ Velocidade corrigida;

$\boldsymbol{U} \boldsymbol{r}=$ Velocidade inicial;

$\boldsymbol{K}=$ Constante de Karman $(0,41)$;

$\boldsymbol{Z r}=$ Altura de referência $(10 \mathrm{~m}$ acima do solo);

$\boldsymbol{Z}^{\circ} \boldsymbol{e} \boldsymbol{d}=$ Coeficientes em função da rugosidade do terreno;

$\boldsymbol{l n}=$ Índice do ângulo de incidência.

Diversos modelos de turbulência são contemplados pelos programas de CFD e devem ser escolhidos de acordo com o caso a ser simulado. CHAM (2015) recomenda o modelo LVEL para simulações que envolvam fluxo de ar e de transferência de calor, simultaneamente.

Definida as características inerentes ao domínio, parte-se para a determinação da malha de avaliação, responsável por capturar os diversos elementos construtivos que interferem no fluxo de ar. Tendo como base o domínio e a geometria criada, o programa gera uma malha padrão. Neste caso houve a necessidade de refinamento da malha para possibilitar a identificação apurada de todos os objetos, resultando em uma malha de avaliação com células de 0,18 x 0,09 x 0,06m.

A seguir, é definido número de iterações das simulações. A ponderação entre a precisão dos resultados e o tempo de simulação determina o número de iterações de uma simulação. Ao longo da simulação, as variáveis interagem e sofrem mudanças nos seus valores até o momento em que se estabilizam. O programa dispõe de gráficos de convergência para a observação deste comportamento a cada iteração. A partir do momento em que as iterações posteriores acarretam mudanças insignificantes nos valores das variáveis, a simulação terá convergido. Para esta pesquisa foi adotado o número de 5000 iterações, resultando em simulações de 3 a 4 horas em um computador com processador Intel Core i5-2400. As condições de contorno do modelo CFD são apresentadas pela Tabela 3.

Tabela 3: Condições de contorno do modelo CFD.

\begin{tabular}{|l|l|}
\hline Condições de contorno do modelo CFD \\
\hline $\begin{array}{l}\text { Temperatura do ar } \\
\text { externo }\end{array}$ & $30,15^{\circ} \mathrm{C}$ \\
\hline $\begin{array}{l}\text { Velocidade do ar } \\
\text { externo }\end{array}$ & $6,0 \mathrm{~m} / \mathrm{s}$ \\
\hline Direção do vento & Nordeste \\
\hline $\begin{array}{l}\text { Forma da malha de } \\
\text { avaliação }\end{array}$ & Hexaedros equivalentes \\
\hline $\begin{array}{l}\text { Dimensão da malha } \\
\text { de avaliação }\end{array}$ & $18 \times 9 \times 6 \mathrm{~cm}$ \\
\hline $\begin{array}{l}\text { Modelo de } \\
\text { turbulência }\end{array}$ & LVEL \\
\hline Número de iterações & 5.000 \\
\hline
\end{tabular}

Fonte: Os autores.

Com todos os parâmetros definidos para a simulação CFD, inicia-se a construção da geometria do ambiente da enfermaria. Por tratar-se de uma geometria simples, a envoltória, mobiliário e usuários foram modelados dentro do próprio FLAIR. O programa disponibiliza uma biblioteca 
própria de materiais para serem aplicados aos elementos modelados. Para representar uma ventilação constante, as aberturas foram modeladas como vazios na geometria, aproveitando ao máximo sua área útil para ventilação. Com exceção dos usuários, todos os demais elementos que compõe a enfermaria são denominados Blockages. Os usuários foram inseridos como objeto Person, o qual não impede o fluxo do ar e representam uma fonte de calor de $45 \mathrm{~W} / \mathrm{m}^{2}$ (CHAM, 2015).

\section{Avaliação integrada}

A avaliação integrada com os modelos de rede e CFD permitiram gerar diversas informações sobre as condições ambientais resultantes da interação da radiação solar e o fluxo de ar para o caso 1 (sem brises) e caso 2 (com brises).

Os resultados obtidos pelo modelo de rede permitiram a análise das trocas de ar por hora $(\mathrm{ACH})$ e do ganho de calor pelas janelas. $\mathrm{O}$ EnergyPlus calcula o número de trocas de ar pela equação abaixo (Equação 3).

$$
A C H=V \cdot F \cdot\left(\mid \text { Tzone }- \text { Todb } \mid+U^{2}\right)
$$

Onde:

$\boldsymbol{A C H}=$ Trocas de ar por hora (air changes per hour); $\boldsymbol{V}=$ Volume do ambiente;

$\boldsymbol{F}=$ Fator de abertura;

$\mid($ Tzone - Todb $) \mid=$ Diferença absoluta entre a temperatura interior e exterior;

$\boldsymbol{U}=$ Velocidade do ar de entrada.

A Figura 7 apresenta um gráfico comparativo entre a velocidade do ar externo e as trocas de ar na enfermaria para ambos os casos no dia 4 (vento norte a $4,9 \mathrm{~m} / \mathrm{s}$ ) e 15 de janeiro (vento sul a 5,2 $\mathrm{m} / \mathrm{s})$. O número de trocas de ar varia entre 0 e 63 $\mathrm{ACH}$. O valor mais alto refere-se ao dia 15 de janeiro às 16hs. A média das trocas de ar é de 27 e $38 \mathrm{ACH}$ nos dias 4 e 15 de janeiro, respectivamente.

Em geral, observa-se que a curva das trocas de ar segue a curva da velocidade do ar externo. Este comportamento não é observado no início da manhã em ambos os dias pelo fato das janelas serem abertas parcialmente quando a temperatura do ar interno e externo está próxima a temperatura de setpoint $\left(22^{\circ} \mathrm{C}\right)$.

Observam-se no gráfico da Figura 7 que para alguns períodos as trocas de ar são nulas mesmo com uma velocidade de ar externo elevada. Isto se explica porque o modelo mantém as janelas fechadas quando a temperatura do ar externo é superior à temperatura do ar interno, conforme foi apresentado no controle de ventilação seletiva do EnergyPlus.

A comparação entre os casos 1 e 2 demonstra que o software EnergyPlus apresenta limitação por não detectar a influência de dispositivos de sombreamento no fluxo interno do ar. Por outro lado, os resultados obtidos indicam uma redução significativa no ganho de calor quando utilizados brises. A Figura 8 demonstra uma redução de 34\% do ganho de calor do caso 2 (1453 W) em relação ao caso $1(2217 \mathrm{~W})$.

Figura 7: Gráfico comparativo entre a velocidade do ar e trocas de ar para cada caso nos dias 4 e 15 de janeiro.

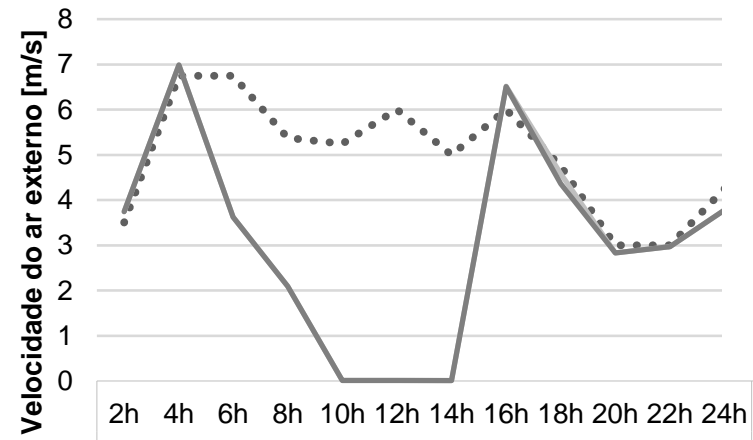

4-Jan

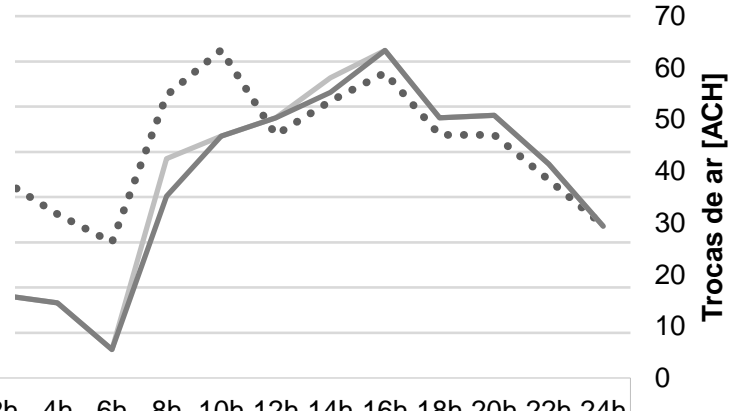

15-Jan

.... Velocid. ar externo $[\mathrm{m} / \mathrm{s}] \longrightarrow$ Caso $1[\mathrm{ACH}] \longrightarrow$ Caso $2[\mathrm{ACH}]$

Fonte: Os autores 
Figura 8: Gráfico da taxa de ganho de calor pelas janelas para cada caso nos dias 4 e 15 de janeiro.

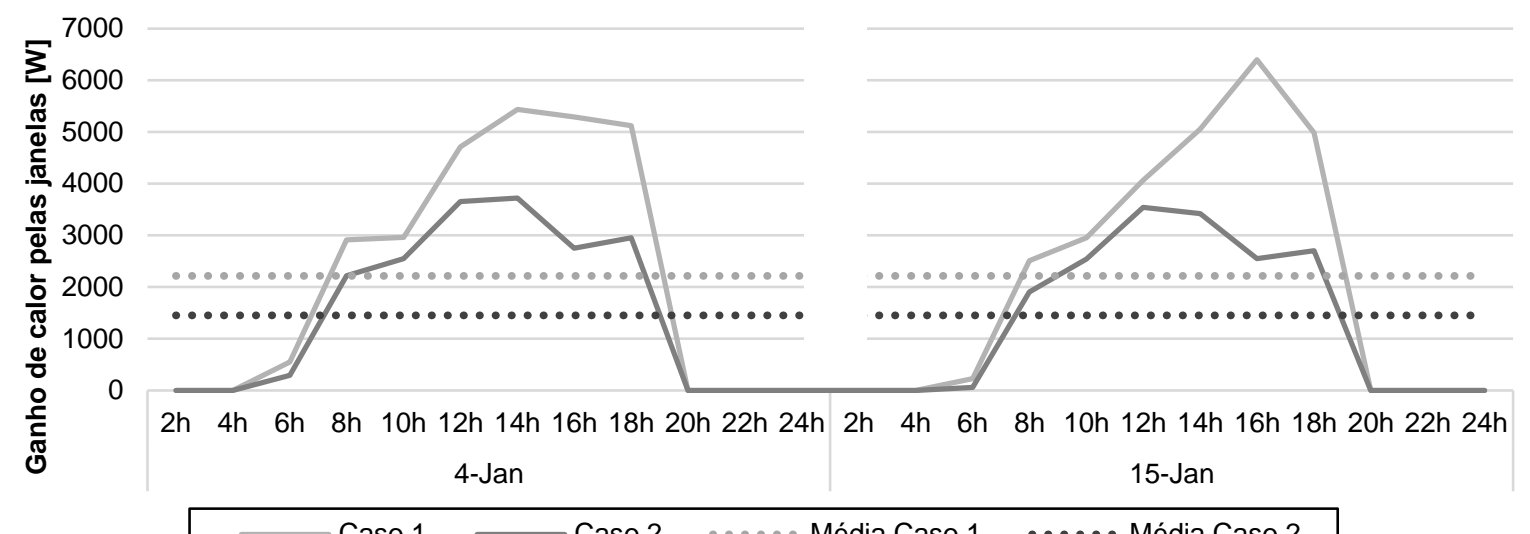

Fonte: Os autores

Os resultados obtidos pelo modelo CFD compensaram a limitação do modelo de rede, uma vez que permitiram a análise da distribuição da velocidade do ar no interior da edificação. Para isto, a investigação é feita no plano horizontal e vertical. O plano horizontal foi traçado a uma altura de $0,9 \mathrm{~m}$, representando o paciente deitado no leito. O plano vertical é exibido por um corte geral passando pelo meio da enfermaria.

A Figura 9 apresenta a enfermaria no plano horizontal com os leitos de internação enumerados. Observa-se um efeito decrescente da velocidade do ar a partir das aberturas de entrada. Neste plano, o fluxo de ar tende a sofrer mudanças de direções, sendo caracterizado como um fluxo turbulento. A variação da velocidade do ar ao longo do percurso pelos leitos é de 0,2 a $2,0 \mathrm{~m} / \mathrm{s}$.

Apesar da proximidade entre os leitos, os pacientes estão expostos a velocidades do ar de valores significativamente diferentes. Elevadas velocidades do ar tendem a provocar desconforto, principalmente por perturbações oriundas de movimentação de objetos. No entanto, muitos autores sugerem que maior movimentação do ar é desejável em ambientes com elevada temperatura do ar (SANTAMOURIS; WOUTERS, 2006). Segundo a ASHRAE Standard 55 (ASHRAE, 2013), velocidades do ar superiores à $1,2 \mathrm{~m} / \mathrm{s}$ permitem um aumento na temperatura operativa de $2,2^{\circ} \mathrm{C}$ para ambientes ventilados naturalmente.

Figura 9: Fluxo de ar no plano horizontal $(\mathrm{h}=0,9 \mathrm{~m})$ para o caso base com vento nordeste à $6.0 \mathrm{~m} / \mathrm{s}$.

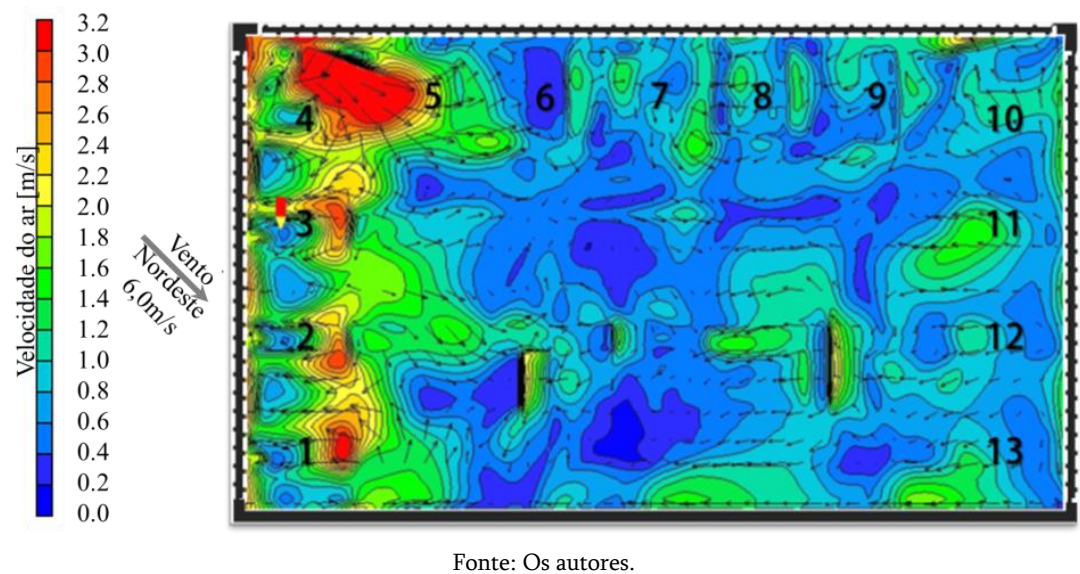

O gráfico apresentado pela Figura 10 demonstra um comportamento semelhante entre as curvas do caso 1 e 2. A enfermaria exposta a ação do vento nordeste à $6,0 \mathrm{~m} / \mathrm{s}$ resulta em elevadas velocidades do ar nos leitos de 1 a 5 . Nestas áreas a velocidade do ar varia de $1,2 \mathrm{~m} / \mathrm{s}$ à $1,8 \mathrm{~m} / \mathrm{s}$ para o caso 1 e de $1,8 \mathrm{~m} / \mathrm{s}$ à $2,0 \mathrm{~m} / \mathrm{s}$ para o caso 2 . Observa-se uma queda brusca na velocidade do ar sobre o leito 6 . 
Nos leitos de 6 a 13, a velocidade do ar varia de 0,2 $\mathrm{m} / \mathrm{s}$ à $1,2 \mathrm{~m} / \mathrm{s}$ em ambos os casos. A velocidade média do ar interno aumenta 20\% do caso $2(1,2$ $\mathrm{m} / \mathrm{s})$ em relação ao caso $1(1,0 \mathrm{~m} / \mathrm{s})$.

Figura 10: Gráfico da distribuição das velocidades do ar sobre os leitos de 1 a 13 em cada caso.

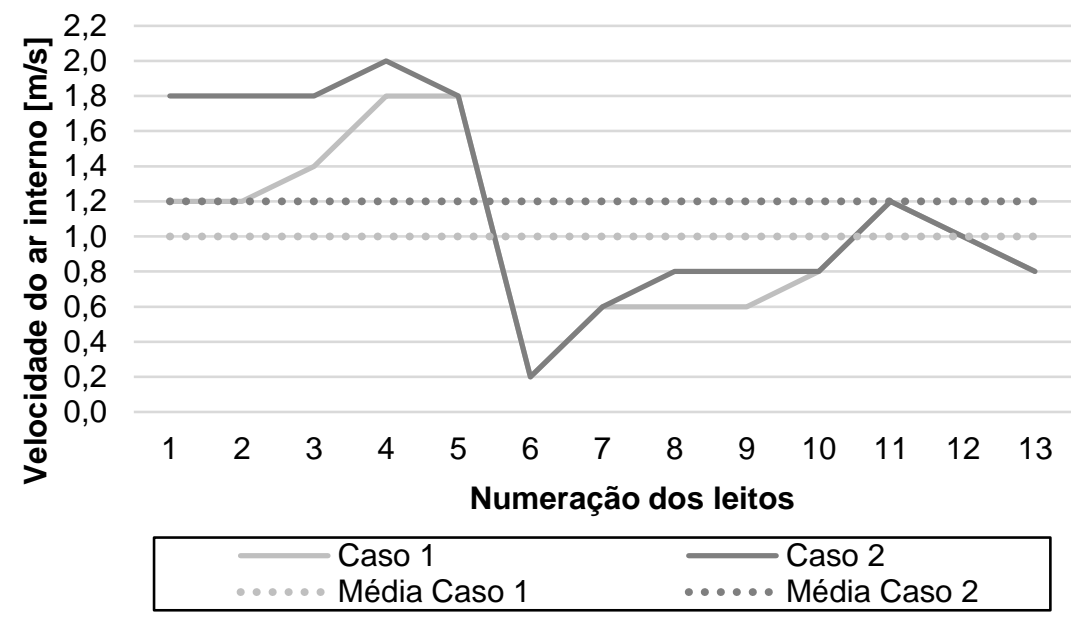

Fonte: Os autores.

O plano vertical representado por um corte geral da enfermaria é apresentado pela Figura 11(a). Observam-se mudanças de direção do fluxo de ar que o caracterizam como turbulento ou laminar.

$\mathrm{Na}$ altura das janelas de entrada e saída, o fluxo do ar tende a ser laminar. A medida que o fluxo de ar atinge o teto e o piso, podem ser observadas importantes zonas de turbulências. As situações de turbulência no teto ocorrem nas aberturas da cobertura que estão próximas a entrada do ar.

O fato de estas aberturas estarem muito próximas da entrada de ar, somado a baixa altura da edificação, resulta em um baixo diferencial de coeficiente de pressão. Assim, ao invés de ocorrer o efeito chaminé desejado, as aberturas funcionam como entrada de ar e provocam zonas de turbulência.

Figura 11: Corte geral com indicação das principais zonas de turbulência (a) e detalhes da entrada do ar na edificação do caso base sem brises (b) e caso 2 com brises (c)
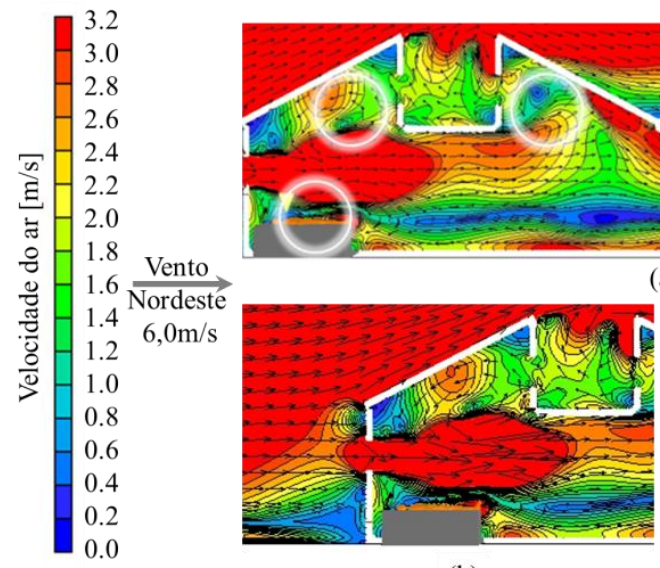

(b)

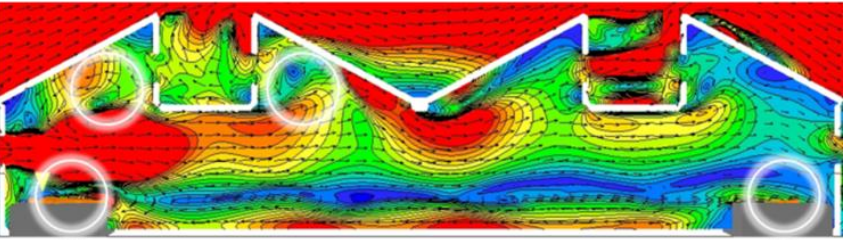

(a)

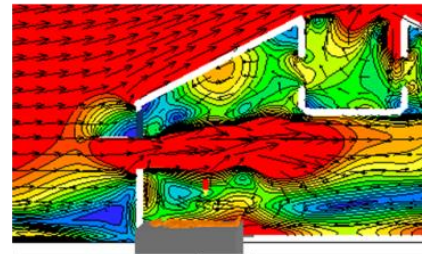

(c)

Fonte: Os autores.

Por outro lado, a condição de turbulência junto ao piso ocorre devido ao encontro do fluxo de ar de entrada e o fluxo de ar que não consegue sair e retorna para o ambiente. Observa-se que toda área entre o piso e a altura do peitoril da janela, inclusive a zona ocupada pelos pacientes sobre os leitos, está sujeita a um fluxo de ar turbulento. A turbulência pode ser considerada como um parâmetro importante para o conforto humano. Fanger e Christensen (1986) afirmam que fluxos do 
ar turbulentos tornam as pessoas mais sensíveis ao desconforto pela movimentação do ar do que fluxo do ar laminar. Além disso, o efeito troca de calor por convecção é maior no fluxo turbulento do que no fluxo laminar, resultando em uma elevação média de $0,7^{\circ} \mathrm{C}$ da temperatura do ar para o conforto térmico (CANDIDO; BITTENCOURT, 2006).

A Figura 11(b) e a Figura 11(c) apresentam cortes em detalhe que revelam o efeito da aplicação dos brises sobre a entrada do ar. Observa-se que o fluxo de ar entra com velocidade do ar mais elevada no edifício provido de brises nas janelas. Neste caso, o brise assume o papel de direcionamento do fluxo de ar para o interior da edificação ao aumentar a diferença de pressão entre a abertura de entrada e de saída.

\section{Considerações finais}

Esta pesquisa apresenta o impacto dos brises no desempenho da ventilação natural em enfermaria em Florianópolis (SC). Os resultados obtidos por meio da integração entre os modelos de rede e CFD suscitaram no encontro de aspectos importantes no que tange a adoção de brises externos e o conforto ambiental que podem ser considerados em outras cidades brasileiras.

Quanto ao ganho de calor pelas janelas, constata-se uma redução significativa de $34 \%$ no caso 2 em que as janelas são providas de brises. Contudo, a especificação desse elemento no projeto deve considerar a geometria de insolação, dimensões e orientação da fachada para maior eficiência.

No âmbito do desempenho da ventilação natural, os modelos CFD permitiram a análise do comportamento do fluxo de ar no interior do ambiente. Sua visualização gráfica possibilita a identificação de áreas de turbulência onde os usuários tendem a aumentar a sensibilidade para trocas de calor por convecção. Além disso, as simulações registram um aumento de $20 \%$ da velocidade média do ar interno no caso $2 \mathrm{em}$ relação ao caso 1. Esse aumento significativo demonstra que, os brises assumem o papel de direcionamento do fluxo de ar para o interior da edificação ao aumentar a diferença de pressão entre a abertura de entrada e de saída.
Diante dos aspectos apresentados, a adoção de brises horizontais e verticais parece apresentar não apenas a usual finalidade de redução do ganho de calor, mas também de auxílio na melhoria do desempenho da ventilação natural no interior da enfermaria. Estudos futuros deverão ser desenvolvidos para analisar o impacto de diferentes geometrias de brises sobre o desempenho da ventilação natural. Destaca-se os benefícios da combinação de duas ferramentas de simulação (EnergyPlus e Phoenics) para futuras pesquisas de análise detalhada da ventilação natural em edifícios.

\section{Referências}

ADAMU, Zulfikar; PRICE, Andrew; COOK, Malcom. Performance evaluation of natural ventilation strategies for hospital wards - A case study of Great Ormond Street Hospital. Building and Environment, Grã-Bretanha: Elsevier Science Ltda, v. 56, p. 211-222, 2012.

American Society of Heating Refrigerating and Air-conditioning Engineers. ASHRAE Standard 55: Thermal Environmental Conditions for Human Occupancy, Atlanta, 2013.

CÂNDIDO, Christina; DE DEAR, Richard; LAMBERTS, Roberto. Combined thermal acceptability and air movement assessments in a hot humid climate. Building and Environment, Grã-Bretanha: Elsevier Science Ltda, v. 46, n. 2, p. 379-385, 2011.

CHAM. Phoenics Ecyclopaedia. Disponível em:<http://www.cham.co.uk/phoenics/d_polis/d_e nc /encindex.htm>. Acesso em: 20 abr. 2016.

FANGER, Povl Ole; CHRISTENSEN, N. Perception of draught in ventilated spaces. Ergonomics, Nova Iorque: Taylor and Francis Group, v. 29, n. 2, p. 215-235, 1986.

GRATIA, Elisabeth.; DE HERDE, André. The most efficient position of shading devices in a doubleskin facade. Energy and Buildings, Grã-Bretanha: Elsevier Science Ltda, v. 39, n. 3, p. 364-373, 2007.

HWANG, Ruey-Lung; LIN, Tzu-Ping; CHENG, Ming-Jen; CHIEN, Jui-Hung. Patient thermal comfort requirement for hospital environments in 
Taiwan. Building and Environment, Grã-Bretanha: Elsevier Science Ltda, v. 42, n. 8, p. 2980-2987, 2007.

LEE, Jeehwan; ALSHAYEB, Mohammed; CHANG, Jae. A Study of Shading Device Configuration on the Natural Ventilation Efficiency and Energy Performance of a Double Skin Façade. Procedia Engineering, Grã-Bretanha: Elsevier Science Ltda, v. 118, p. 310-317, 2015.

PEREIRA, Helena A. C.; MELO, Ana Paula; VERSAGE, Rogério; SORGATO, Márcio; LAMBERTS, Roberto. Manual de simulação computacional de edifícios naturalmente ventilados no programa Energyplus: Versão 8.0. Laboratório de Eficiência Energética em Edificações, Departamento de Engenharia Civil, Universidade Federal de Santa Catarina, Florianópolis, 2013. Disponível em: $<$ http://www.labeee.ufsc.br/sites/default/files/discip linas/Manual_Ventilacao_v8_0.pdf $>$. Acesso em: 5 nov. 2016.

SAFER, Nassim; WOLOSZYN, Monika; ROUX, Jean Jacques. Three dimensional simulation with a CFD tool of the airflow phenomena in single floor doubleskin façade equipped with a venetian blind. Solar Energy, Grã-Bretanha: Elsevier Science Ltda, v. 79, n. 1, p. 193-203, 2004.

SANTAMOURIS, Mat; DESCALAKI, E.; BALARAS, Constantinos; GAGLIA, Athina; Energy performance and energy conservation in health care buildings in hellas. Energy Conversion and Management, Grã-Bretanha: Elsevier Science Ltda, v. 35, n. 4, p. 293-305, 1994.

SANTAMOURIS, Mat. Natural Ventilation in Buildings: A Design Handbook. Londres: James and James Limited, 1998, 356p.

SANTAMOURIS, Mat; WOUTERS, Peter. Building Ventilation: The State of the Art. Londres: Earthscan, 2006, 313p.

SANTANA, Marina Vasconcelos. Influência de Parâmetros Construtivos no Consumo de Energia de Edifícios de Escritório Localizados em Florianópolis, SC. Dissertação (Mestrado em Engenharia Civil) Programa de Pós-graduação em Engenharia Civil, Universidade Federal de Santa Catarina, Florianópolis, 2006.
SOUZA, Fábio. Notas de consultoria sobre o software Phoenics com a empresa Safesolution. Florianópolis, 2015.

SZKLO, Alexandre Salem; SOARES, Jeferson Borghetti; TOLMASQUIM, Maurício Tiomno. Energy consumption indicators and CHP technical potential in the Brazilian hospital sector. Energy Conversion and Management, Grã-Bretanha: Elsevier Science Ltda, v. 45, n. 13-14, p. 20752091, 2004.

ZHAI, Zhiqiang. Application of Computational Fluid Dynamics in Building Design: Aspects and Trends. Indoor and Built Environment, Los Angeles: SAGE Publications, v. 15, n. 4, p. 305313, 2006.

ZHANG, Rui; LAM, Khee Poh; YAO, Shi-chune; ZHANG, Yongjie. Coupled EnergyPlus and computational fluid dynamics simulation for natural ventilation. Building and Environment, Grã-Bretanha: Elsevier Science Ltda, v. 68, p. 100113, 2013. 